\title{
Flame Retardance and Char Analysis of Environmental Friendly Polyurethane Hyperbranched Organic-Inorganic Hybrid Using the Sol-Gel Method
}

\author{
Ming-Yuan Shen ${ }^{1}$, Chen-Feng Kuan ${ }^{2}$, Hsu-Chiang Kuan ${ }^{3}$, Cing-Yu Ke ${ }^{4}$ and Chin- Lung Chiang*5 \\ 1 National Chin-Yi University of Technology; hbj678@gmail.com \\ 2 Far East University; cfkuan@mail.feu.edu.tw \\ 3 Far East University; hckuan@mail.feu.edu.tw \\ 4 Hung-Kuang University; h22432003@gmail.com \\ 5 Hung-Kuang University; dragon@sunrise.hk.edu.tw \\ * Correspondence: dragon@sunrise.hk.edu.tw; Tel.: +886-4-26318652-4008
}

\begin{abstract}
This study used the sol-gel method to synthesize a non-halogenated hyperbranched flame retardant containing nitrogen, phosphorus and silicon, HBNPSi, which was then added to a polyurethane (PU) matrix to form an organic-inorganic hybrid material. Using ${ }^{29} \mathrm{Si}$ nuclear magnetic resonance, energy-dispersive $\mathrm{X}$-ray spectroscopy of $\mathrm{P}$ - and Si-mapping, scanning electron microscopy, and X-ray photoelectron spectroscopy, this study determined the organic and inorganic dispersity, morphology, and flame retardance mechanism of the hybrid material. The condensation density of the hybrid material PU/HBNPSi was found to be $74.4 \%$. High condensation density indicates a dense network structure of the material. The P- and Si-mapping showed that adding inorganic additives in quantities of either $20 \%$ or $40 \%$ results in homogeneous dispersion of the inorganic fillers in the polymer matrix without agglomeration, indicating that the organic and inorganic phases had excellent compatibility. In the burning test, adding HBNPSi to PU resulted in the material passing the UL-94 standard at the V2 level, unlike the pristine PU, which did not meet the standard. The results demonstrated that after non-halogenated flame retardant was added to $\mathrm{PU}$, the material's flammability and dripping were lower, thereby proving that flame retardants containing elements such as nitrogen, phosphorus, and silicon exert an excellent flame retardant synergistic effect.
\end{abstract}

Keywords: sol-gel method; polyurethane; flame retardant; organic-inorganic hybrid; synergistic effect

\section{Introduction}

Polyurethane (PU) can appear in many forms, such as foam, adhesive, paint, and elastomer. Because of its favorable mechanical properties and resistance to chemicals and wear, PU is widely used in the automobile, textile, sports equipment, shoe sole, and paint industries among others [1-3]. $\mathrm{PU}$ is the most common commercial polymer material in daily life. However, it has some weaknesses such as low thermal stability and high flammability. For example, when PU is heated to $80^{\circ} \mathrm{C}-90^{\circ} \mathrm{C}$, its mechanical properties rapidly deteriorate. When heated to over $200^{\circ} \mathrm{C}$, severe pyrolysis occurs and it becomes flammable, increasing the risk of a fire hazard. Therefore, improving the flame retardance of PU has been a critical task in the development of polymer materials $[1,4,5]$.

Compared with halogenated flame retardants, non-halogenated flame retardants have attracted great attention because during their combustion, less hazardous gases or smoke is produced. Flame retardants can play a role in the gas phase or condensed phase. Halogenated flame retardants are typically in the gas phase, whereas flame retardants containing phosphorus and nitrogen can be in 
either phase [4, 6-7]. Flame retardants containing siloxane have a main chain of $\mathrm{Si}-\mathrm{O}$. Because the energy of the $\mathrm{Si}-\mathrm{O}$ bond is high and the $\mathrm{Si}-\mathrm{O}$ chain is resilient, forming $\mathrm{SiO}_{2}$, these flame retardants exhibited outstanding thermal stability under high temperature [8].

The PU used in this study has a wide range of applications. However, it has fatal disadvantages such as flammability and dripping. This study employed the sol-gel method to prepare a hybrid material of PU and flame retardants containing nitrogen, phosphorus, and silicon. ${ }^{29} \mathrm{Si}$ nuclear magnetic resonance (NMR) was used to observe the condensation density. The UL-94 standard was then used to evaluate the flame retardance of the hybrid material. Scanning electron microscopy (SEM) was used to examine the morphology of the char of hybrid material, whereas X-ray photoelectron spectroscopy (XPS) was adopted to determine char composition to observe the mechanism of burning.

\section{Experimental}

\subsection{Materials}

Isophorone diisocyanate (IPDI) and dibutyltin dilaurate (DBTDL) were purchased from Alfa Aesar CO., Shore Road, Heysham, LA3 2XY, England. ARCOL POLYOL 1021(Polyol) was purchased from Bayer Material Science Taiwan Limited. 1, 4-butanediol (1, 4-BD), was purchased from Acros Chemical Co, New Jersey, USA. 3-Isocyanatopropyltriethoxysilane (IPTS) was purchased from GELEST, Inc., 11 steel Rd. EAST, Morrisville, PA, USA. Triglycidyl isocyanurate(TGIC) was purchased from TCI, Jokyo, 10-(2,5-Dihydroxyphenyl)-10H-9-oxa-10-phospha-phenantbrene-10-oxide (DOPO-BQ) was purchased from Sigma-Aldrich Co Ltd, Taipei, Taiwan. Anhydrous stabilized tetrahydrofuran (THF) was obtained from Lancaster Co., Morecambe, Lancashire, U.K. Hydrogen chloride ( $\mathrm{HCl})$ was purchased from ECHO Chemical Co., LTD, Taiwan.

\subsection{Preparation of DOPOBQ-IPTS-TGIC}

First, DOPO-BQ $(7.58 \mathrm{~g})$ and IPTS (5.78 g) were added into a $100 \mathrm{~mL}$ serum bottle, and then added $80 \mathrm{~mL}$ of THF solvent and $0.2 \mathrm{~g}$ of metal catalyst DBTDL. The aforementioned reactants were stirred at $60{ }^{\circ} \mathrm{C}$ and allowed the substances to react for 2 hours. Subsequently, we added $0.72 \mathrm{~mL}$ of DI water into THF, instilled HCI, and adjusted the $\mathrm{pH}$ value to 4 ; the product of the sol-gel reaction was HBPSi. Additionally, TGIC (6.95 g) was dissolved in THF and conducted a sol-gel reaction for 2 hours on HBPSi. After the temperature reached $60{ }^{\circ} \mathrm{C}$, TGIC was slowly added into HBPSi, and allowed them to react at $60{ }^{\circ} \mathrm{C}$ for 2 hours. This formed a hyperbranched nitrogen-phosphoroussilicon (HBNPSi) flame retardant which was dissolved in THF, and then took place the addition reaction with prepolymer to form nanocomposites. Its reaction is presented in Scheme 1. 

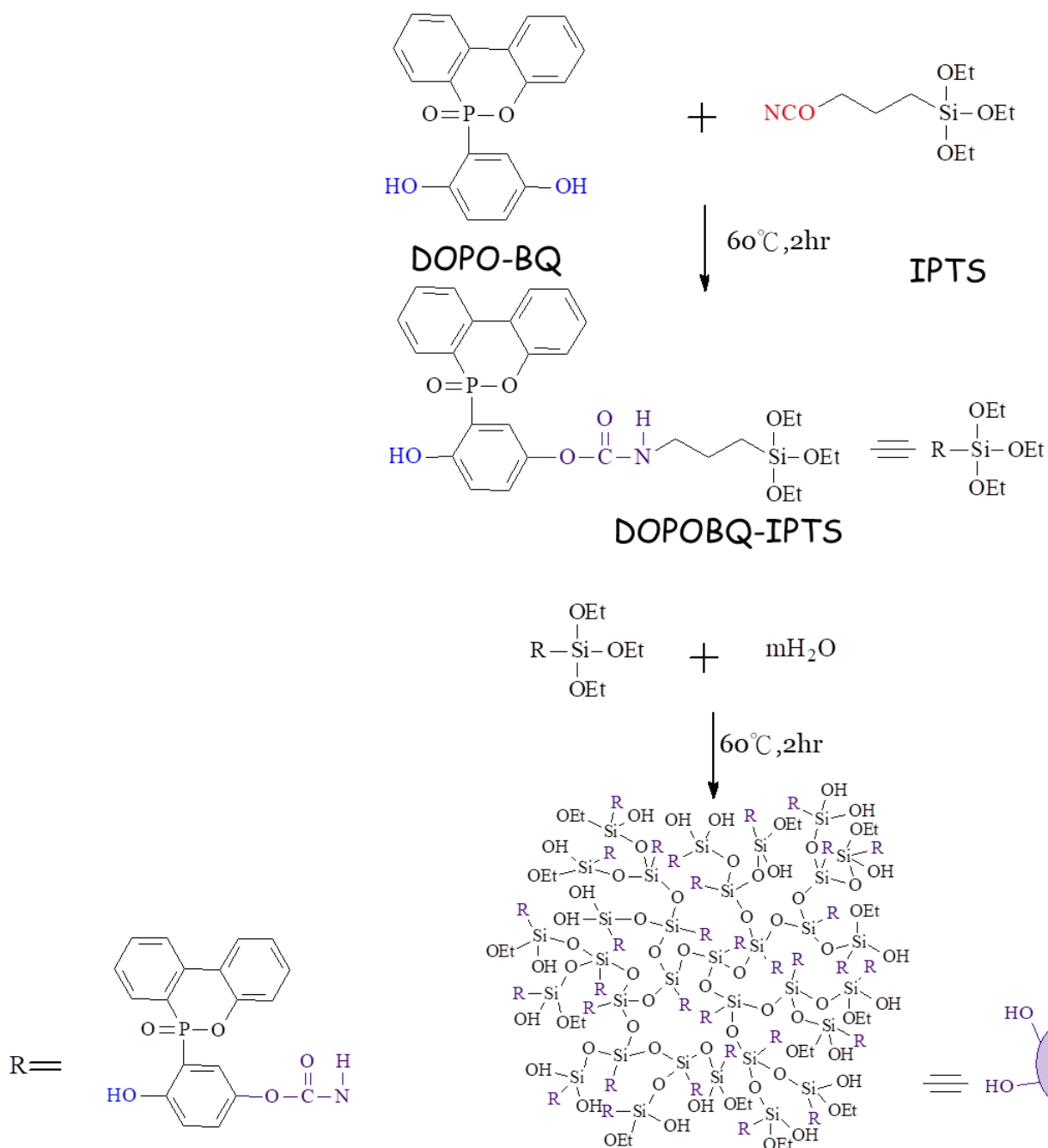

HBPSi
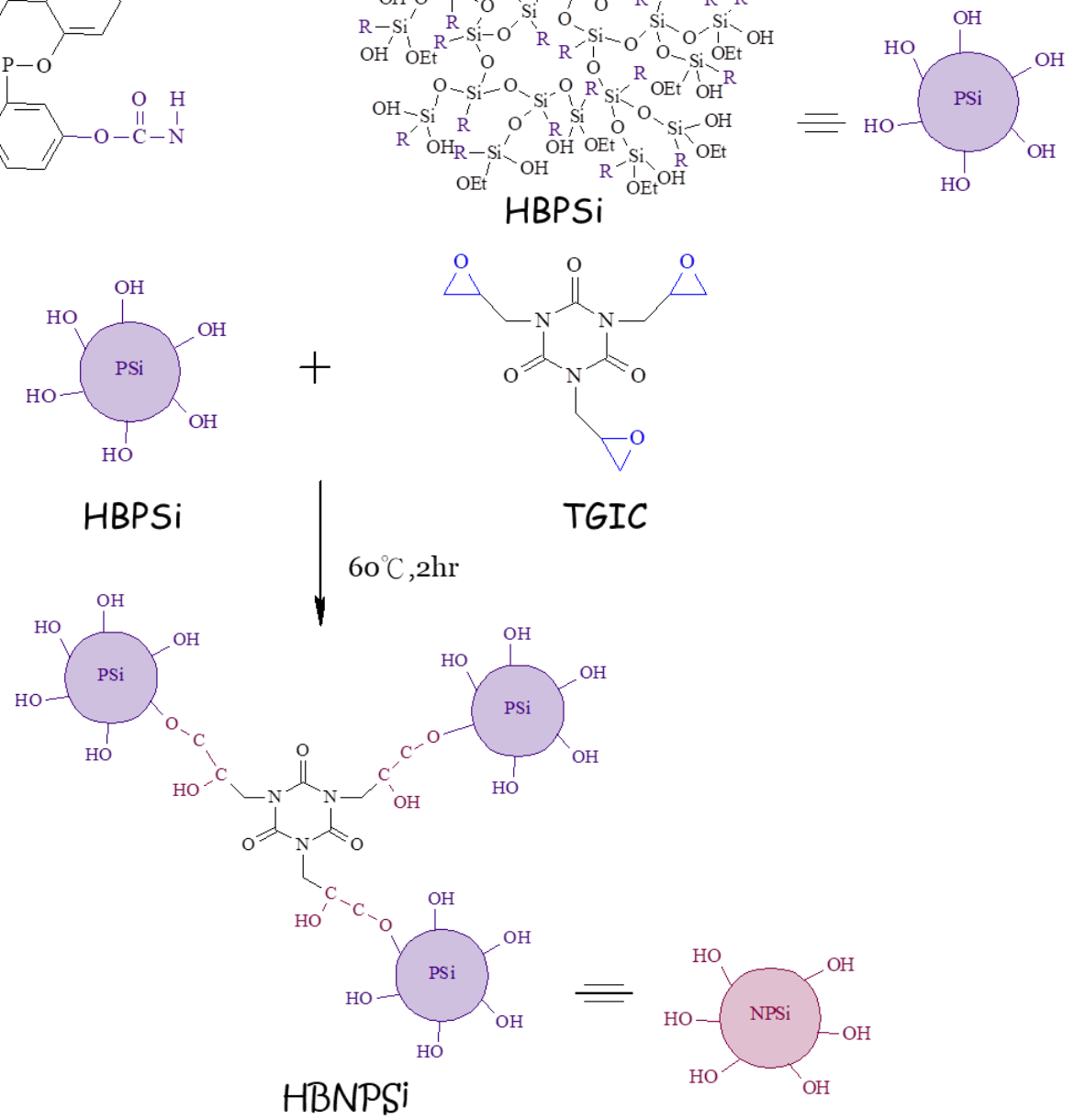

Scheme 1 the reaction of HBNPSi. 


\subsection{Preparation of PU/HBNPSi hybrid}

IPDI (9.88 g) and Polyol ( $20 \mathrm{~g})$ were added into a four-necked bottle in a nitrogen environment; the mixture was stirred by a magnetic stirrer at $60{ }^{\circ} \mathrm{C}$. Subsequently, DBTDL catalyst $(0.3 \mathrm{~g})$ was added into the four-necked bottle for a simultaneous reaction to form prepolymer. Following 2 hours of reaction, HBNPSi was slowly dripped into the four-necked bottle. After 2 hours of reaction, 1- $4 \mathrm{BD}$ $(0.8 \mathrm{~g})$ was also allowed to react for 2 hours and observed whether viscosity increased. After viscosity increased for any sample, that sample was poured into a polytetrafluoroethylene mold and placed it into a vacuum oven for 24 hours of de-aeration. After the temperature reached $60{ }^{\circ} \mathrm{C}$, it was placed in another circulating oven for 24 hours. When the temperature reached $60{ }^{\circ} \mathrm{C}$, the finished product was withdrawn and stored at room temperature for cooldown, thereby completing preparation of PU/HBNPSi. Its reaction formula is presented in Scheme 2.

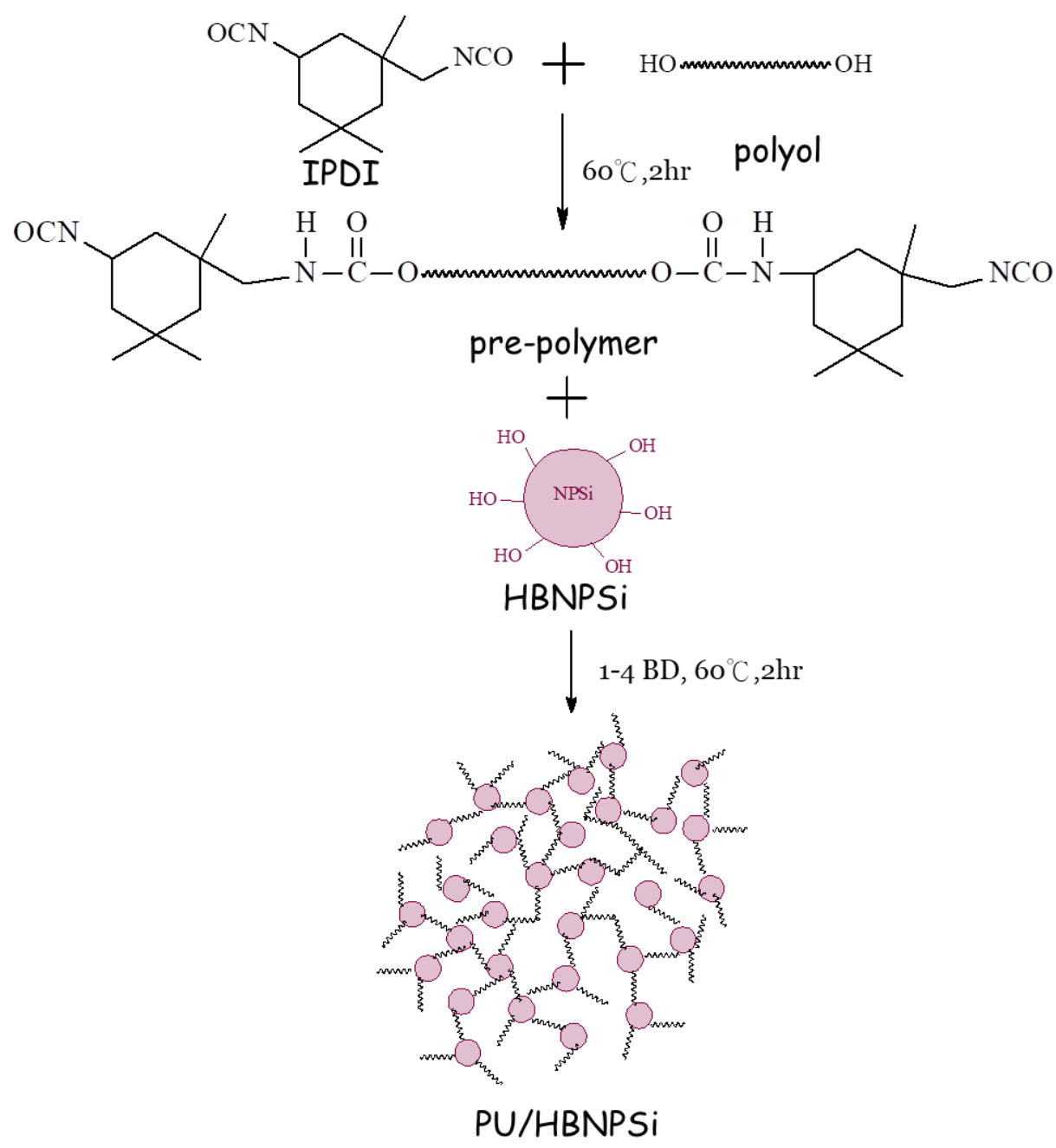

\subsection{Measurements}

Scheme 2 the reaction of PU/HBNPSi.

${ }^{29}$ Si NMR was performed by a Bruker DSX-400WB, Germany. The samples were treated at 180 ${ }^{\circ} \mathrm{C}$ for $2 \mathrm{hr}$ and then ground into fine powder. The LOI is defined as the minimum fraction of $\mathrm{O}_{2}$ in a mixture of $\mathrm{O}_{2}$ and $\mathrm{N}_{2}$ that will just support flaming combustion. The LOI test was performed according to the testing procedure of the ASTM D 2836 Oxygen Index Method, with a test specimen bar 7-15 cm long, $6.5 \pm 0.5 \mathrm{~mm}$ wide, and $3.0 \pm 0.5 \mathrm{~mm}$ thick. The sample bars were suspended vertically and ignited by a Bunsen burner. The flame was removed and the timer was started. The concentration of oxygen was increased if the flame on the specimen was extinguished before burning for $3 \mathrm{~min}$ or burning away $5 \mathrm{~cm}$ of the bar. The oxygen content was adjusted until the limiting concentration was determined. The vertical burning test was done inside a fume hood. Samples were held vertically with tongs at one end and burned from the free end. Samples were exposed to ignition 
source for $10 \mathrm{~s}$ then they were allowed to burn above a cotton wool until both sample and cotton wool extinguished. Observable parameters were recorded to assess fire retardance. The UL 94 test classifies the materials as V-0, V-1 and V-2 according to the time period needed before self-extinction and the occurrence of flaming dripping after removing the ignition source. $\mathrm{V}-0$ is the most ambitious and desired classification. High resolution X-ray photoelectron spectrometer (HR-XPS, ULVAC-PHI, Inc., Kanagawa-ken, Japan): The sample is crushed into powder, and the sample is then adhered to the aluminum sheet with small round holes, which is mainly used for detecting the sample surface as well as the element composition and distribution in vertical directions, in addition to implementing analysis on the links of element substances. The morphology of the fractured surface of the composites was studied under a scanning electron microscope (SEM) (JEOL JSM 840A, Japan). Energy-dispersive X-ray spectroscopy (EDX) was used to observe the distributions of Si and P atoms in the hybrid were obtained from SEM EDX mapping (JEOL JSM 840A, Japan).

\section{Results and discussion}

\section{$3.1{ }^{29}$ Si NMR}

Solid-state ${ }^{29} \mathrm{Si}$ NMR spectrometry was used to determine the structure of the PU/HBNPSi hybrid material, and the DOPO-BQ-IPTS reaction process and its degree of hydrolysis condensation were obtained using the sol-gel method. Because one end of IPTS was terminated with three tri-alkoxy groups $(\mathrm{T})$, the end of the prepolymer had a $\mathrm{T}$-shaped structure. The other end was terminated with an organic chain - an - $\mathrm{NCO}$ functional group - that reacted with the $-\mathrm{OH}$ functional group in DOPO-BQ. The T-end further hydrolyzed and condensed to form a network structure of Si-O-Si, which was more stable. According to the degree of hydrolysis and condensation, the single-, double-, and triple-replacement absorption peaks located at -45 to $-48 \mathrm{ppm},-56$ to $-62 \mathrm{ppm}$, and -66 to -69 ppm indicate the $\mathrm{T}^{1}[10,11], \mathrm{T}^{2}[10,12]$, and $\mathrm{T}^{3}[10,11]$ structures, respectively.

Fig. 1 presents the solid-state ${ }^{29} \mathrm{Si}$ NMR spectra of the PU/HBNPSi hybrid material. The hybrid material had the $\mathrm{T}$-structure, primarily $\mathrm{T}^{3}$. Using peak separation treatments, the $\mathrm{T}^{1}, \mathrm{~T}^{2}$, and $\mathrm{T}^{3}$ areas could be identified. Then, the following equation was used to calculate the condensation density, $\operatorname{Dc}(\%)[11]$,

$$
\operatorname{Dc}(\%)=\frac{1 \times\left(\% \text { area } T^{1}\right)+2 \times\left(\% \text { area } T^{2}\right)+3 \times\left(\% \text { area } T^{3}\right)}{3}
$$

The condensation density (Dc\%) of the hybrid material PU/HBNPSi was calculated to be $74.4 \%$. Higher Dc\% indicates that a material has a denser network structures. The Si-O-Si bonded into an excellent network structure, and the $\mathrm{Si}-\mathrm{O}$ bond had high bond energy. The hybrid material thus had high thermal stability and flame retardance. The results are summarized in Table 1. 


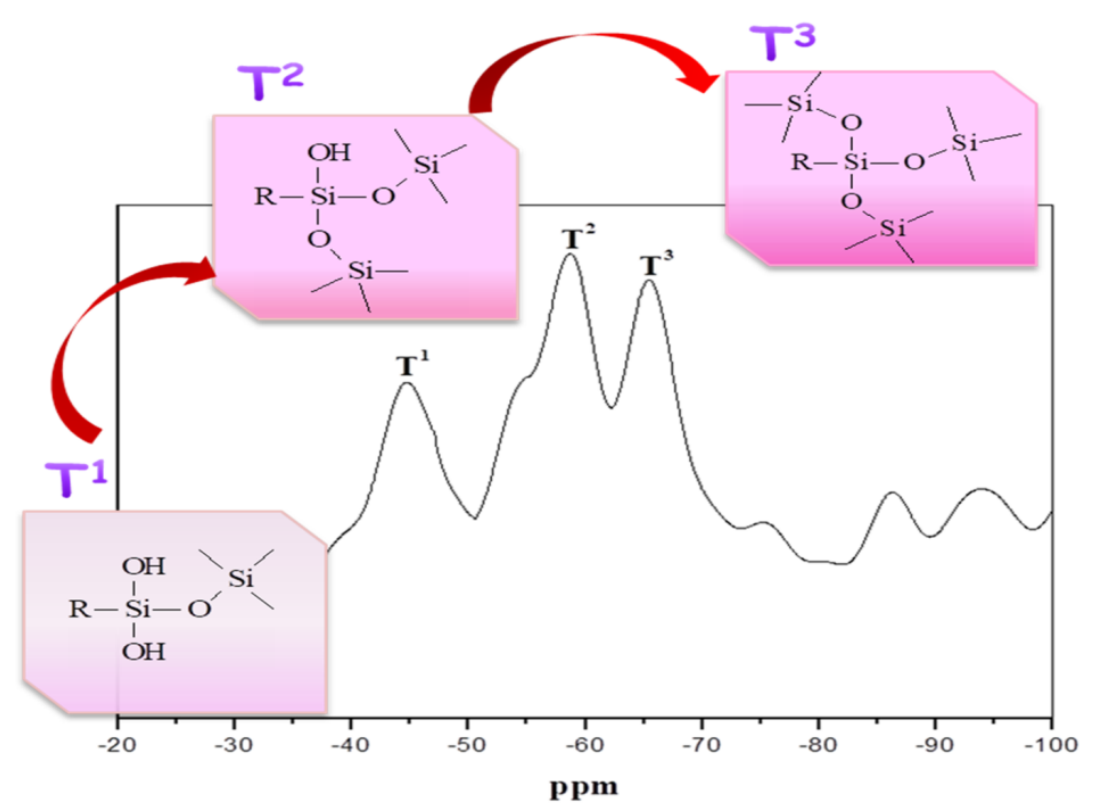

Fig. 1 Solid-state ${ }^{29}$ Si NMR spectra of PU/HBNPSi.

Table 1 Distribution of area proportion.

\begin{tabular}{cccc}
\hline & \multicolumn{3}{c}{ Area (\%) } \\
Sample NO. & $\mathrm{T}^{1}$ & $\mathrm{~T}^{2}$ & $\mathrm{~T}^{3}$ \\
\hline PU/HBNPSi 40\% & 24.3 & 44.3 & 36.8 \\
\hline
\end{tabular}

\subsection{P- and Si-mapping of EDX}

This study determined the compatibility of pristine PU and HBNPSi. Two phases were obtained and demonstrated differences under different interaction forces. The P- and Si-mapping of energy-dispersive X-ray spectroscopy was utilized to determine whether the dispersibility and homogeneity were favorable or whether agglomeration occurred when the inorganic phase was mixed with the organic phase. Favorable dispersibility indicates that two phases have excellent compatibility, which is crucial in a hybrid material.

Fig. 2 displays P- and Si-mapping of 20\% and 40\% PU/HBNPSi. The images show the dispersion of the inorganic elements $\mathrm{P}$ and $\mathrm{Si}$ in the organic phase. Each bright dot represents $\mathrm{P}$ or Si. The figure reveals that the inorganic substances in both the $20 \%$ and $40 \%$ PU/HBNPSi were dispersed favorably in the matrix and that the material was homogeneous. No agglomeration was observed, indicating that the compatibility between the organic and inorganic phases was excellent. The amount of $\mathrm{P}$ and $\mathrm{Si}$ in the material increased as the HBNPSi content was increased. 


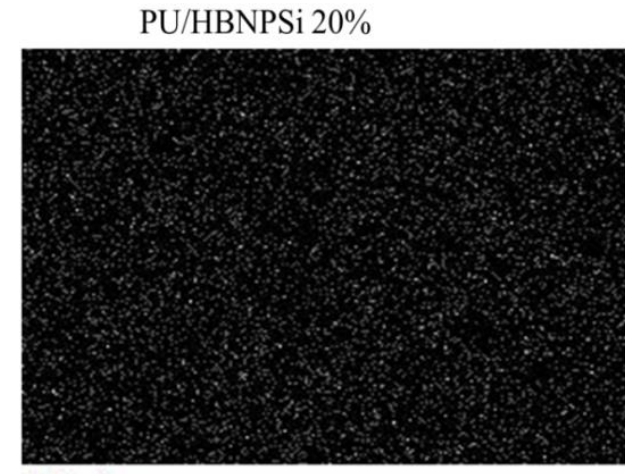

P Ka1

PU/HBNPSi $40 \%$

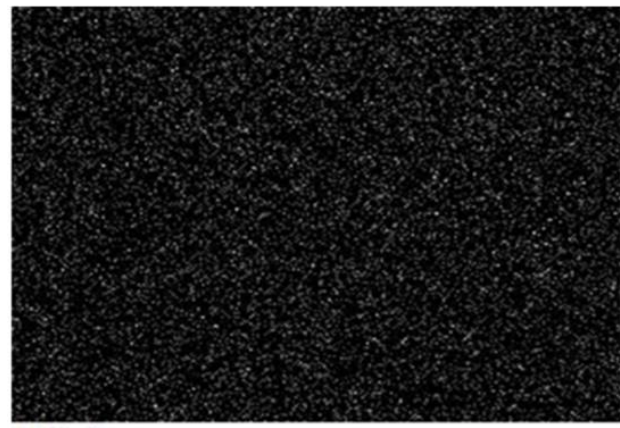

P Ka1

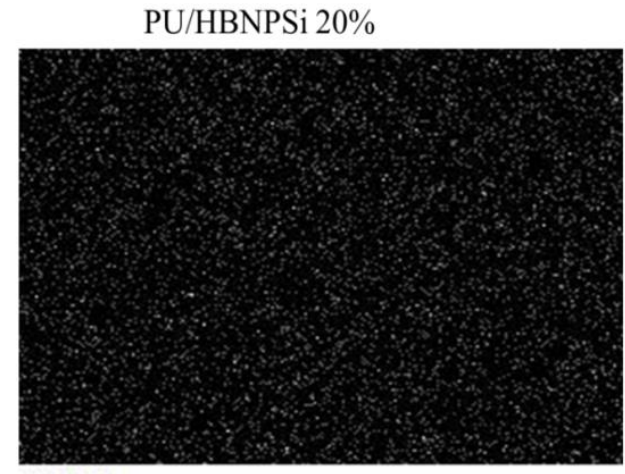

Si Ka1

PU/HBNPSi $40 \%$

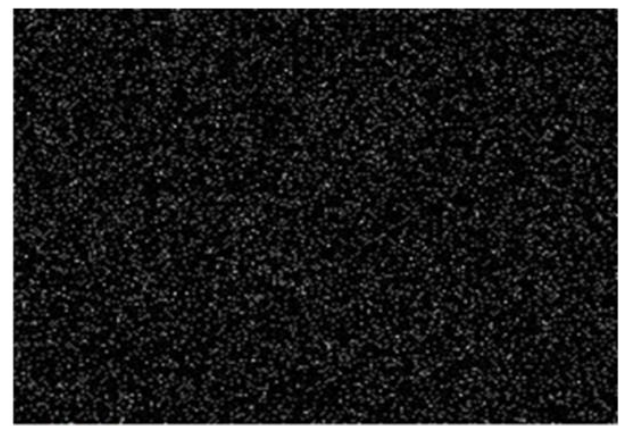

Si Ka1

Fig. 2 Mapping photograph of P 、 Si-containing hybrid : PU/HBNPSi.

\subsection{Flame retardance analysis}

In the UL-94 test, a standardized ignition specimen is combusted and the total burning duration (the sum of two burning durations) must meet the standard; additionally, during the burning process, dripping, which could ignite the cotton beneath the specimen, must not occur. The flame retardance of polymeric material is classified into the V-0, V-1, and V-2 levels. Fig. 3 and Table 2 reveal that the pristine PU failed and did not achieve any level. Dripping was observed, and the drips ignited the cotton below. As the concentration of HBNPSi in the material was increased to $40 \%$, two flame burning duration of the PU/HBNPSi hybrid material are 0.7 and $16.1 \mathrm{~s}$, respectively. The sum of two burning durations was $16.8 \mathrm{~s}$. However, because dripping occurred, the material was graded as V-2. HBNPSi had excellent flame retardance because during pyrolysis, the $\mathrm{N}$ and $\mathrm{P}$ in the structure became gaseous, capturing free radicals and play a role in the condensed phase, catalyzing the formation of char. Additionally, Si migrated across the surface [12-13], forming a dense $\mathrm{SiO}_{2}$ structure that protected the interior of the materials. The benzene ring of DOPO-BQ provided the source for char formation, and the char layer resisted burning under high temperature. 


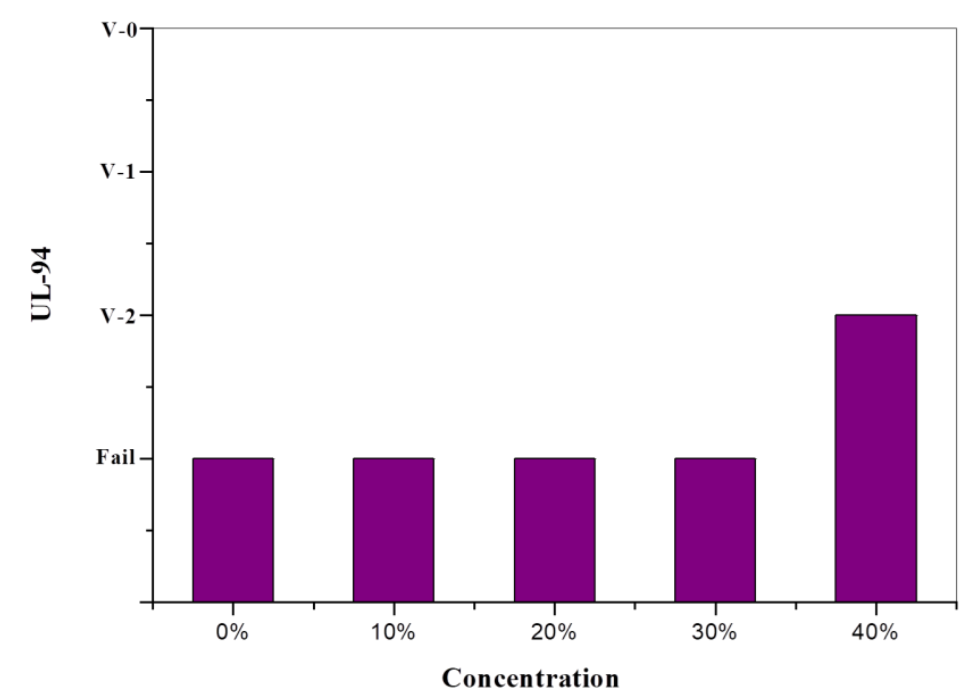

Fig. 3 Effect of various HBNPSi concentration on the UL-94 of PU/HBNPSi hybrid.

Table 2 The flame retardance of PU/HBNPSi hybrid by UL-94 values.

\begin{tabular}{cccc}
\hline Sample & & UL-94 & \\
\cline { 2 - 4 } & $\mathrm{t}_{1}+\mathrm{t}_{2}(\mathrm{~s})$ & Ranking & Dripping \\
\hline Pristine PU & $>30$ & Fail & Yes \\
PU/HBNPSi 10\% & $>30$ & Fail & Yes \\
PU/HBNPSi 20\% & $>30$ & Fail & Yes \\
PU/HBNPSi 30\% & $>30$ & Fail & Yes \\
PU/HBNPSi 40\% & 16.8 & V2 & Yes \\
\hline
\end{tabular}

\subsection{Morphology analysis}

SEM was used to observe the morphology of the hybrid material and determine its surface microtopography, particle size and surface nucleation. Fig. 4(a) shows that the surface of the pristine PU was smooth and homogeneous before burning, without phase separation. Fig. 4(b) displays the surface of the burned pristine PU. Because pristine PU is highly flammable and is molten after burning, some wave patterns can be observed in the SEM image. Fig. 4(c) shows the surface of the 20\% PU/HBNPSi before burning; it was generally smooth and without phase separation despite the addition of HBNPSi. Fig. 4(d) displays the surface of 20\% PU/HBNPSi after burning. Some Si particles can be seen because Si migrated across the surface during burning. However, because insufficient char was formed, the heat blocking effect was weak, calling to mind UL-94. Therefore, 20\% 
PU/HBNPSi was flammable. Fig. 4(e) shows the surface of 40\% PU/HBNPSi before burning and that the surface had discrete HBNPSi particles. Although the addition loading was $40 \%$, no phase separation was observed. Fig. 4(f) shows the surface of $40 \%$ PU/HBNPSi after burning. A dense char layer covered this surface because $\mathrm{P}$ was dehydrated and catalyzed into char and Si migrated across the surface while burning to form a dense char layer through condensed phase. Both P and Si covered the material surface [11-13], blocking the transmission of gas and flame and increasing thermal stability.
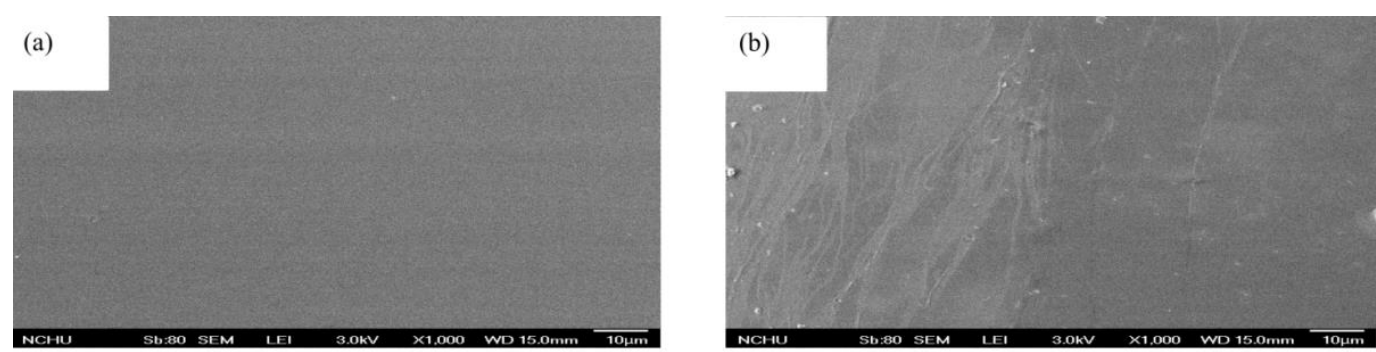

(c)

(d)
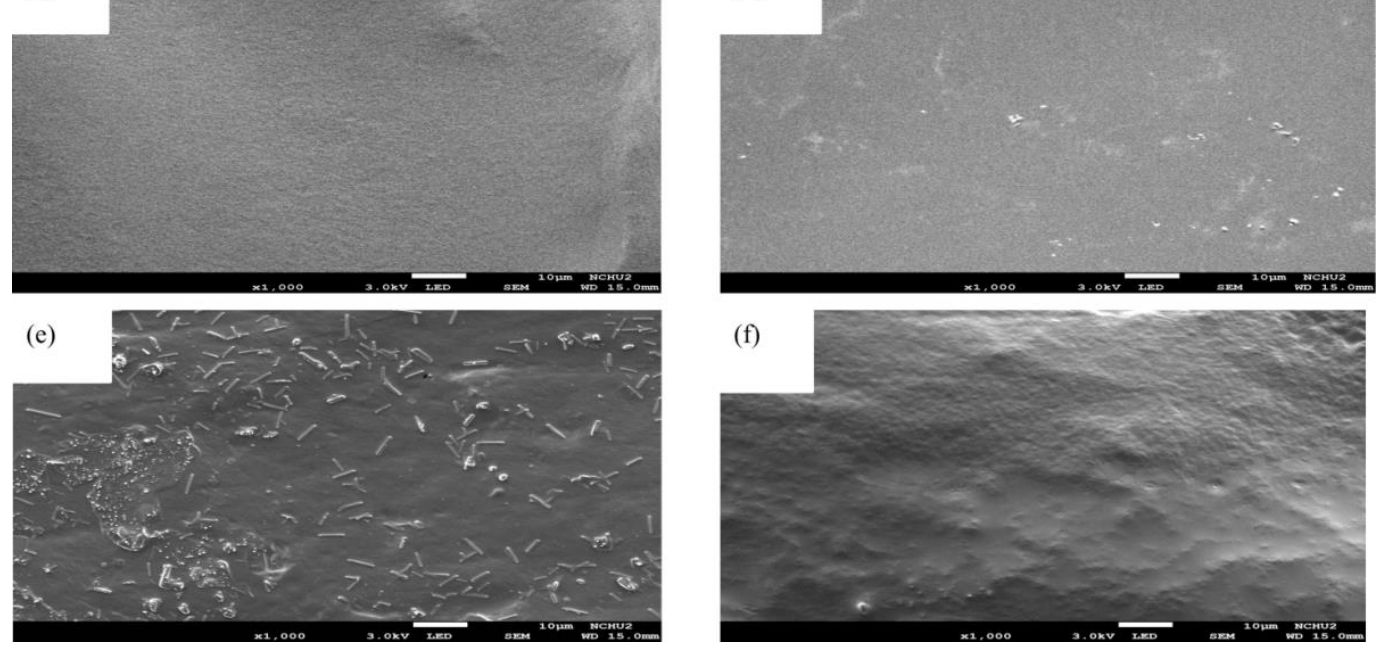

Fig. 4 SEM micrographs of composites (a)pristine PU (before burning) $(\times 1 \mathrm{~K}) \cdot(\mathrm{b})$ pristine PU (after burning) $(\times 1 \mathrm{~K}) 、(\mathrm{c}) \mathrm{PU} / \mathrm{HBNPSi} 20 \%$ (before burning)( $\times 1 \mathrm{~K}) \cdot(\mathrm{d}) \mathrm{PU} / \mathrm{HBNPSi} 20 \%($ after burning) $(\times 1 \mathrm{~K})$. (e)PU/HBNPSi 40\%(before burning)(×1K) 、(f)PU/HBNPSi 40\%(after burning)(×1K).

\subsection{XPS char analysis}

XPS was used to examine the changes of chemical bonds in the PU/HBNPSi hybrid material at room temperature and after being burned at $800^{\circ} \mathrm{C}$ in a high temperature furnace. Additionally, after flame retardant was added to PU, the functional group changes before and after the hybrid was burned were observed. Peak separation method was used to calculate the material's anti-oxidation characteristics. The results are presented in Figs. 5-10 and Tables 3 and 4.

Fig. 5 displays XPS rough scans illustrating the elemental composition of the pristine PU, 10\% $\mathrm{PH} / \mathrm{HBNPSi}$ at room temperature, 40\% $\mathrm{PH} / \mathrm{HBNPSi}$ at room temperature, and $40 \% \mathrm{PU} / \mathrm{HBNPSi}$ after being burned at $800^{\circ} \mathrm{C}$. The scan in Fig. 5(a) indicates three elements: $\mathrm{C}, \mathrm{O}$, and N. For the hybrid material containing 20\% flame retardant (Fig. 5(b)), P and Si were observed in addition to C, O, and N. The XPS rough scan obtained after DOPO-BQ and IPTS were reacted verifies that the hybrid material contained P and Si. Fig. 5(c) presents the rough scan for the hybrid material containing $40 \%$ of a $\mathrm{SiO}_{2}$ inorganic substance. Because the additive content was higher than for the $10 \%$ hybrid material, the $\mathrm{P}$ 
and $\mathrm{Si}$ content were higher. Fig. 5(d) shows that the hybrid material was $40 \% \mathrm{SiO}_{2}$ after being burned. Burning at high temperature led to a slight increase in the amount of $\mathrm{P}$ and $\mathrm{Si}$ in the hybrid material, because during the burning process, $\mathrm{P}$ was dehydrated and formed char and Si migrated across the surface [12-13]. Together, these elements formed a layer of char containing P and Si that protected the material.

Figs. 6-10 present scans showing Cls, Ols, P2p, and Si2p bonding in the materials at room temperature and after being burned at $800^{\circ} \mathrm{C}$. Six functional groups are observed in the Cls spectra: those at $284 \mathrm{eV}(\mathrm{C}-\mathrm{C}$ and $\mathrm{C}-\mathrm{H})$ [14], $285.4 \mathrm{eV}(\mathrm{C}-\mathrm{N})$ [15], $288.5 \mathrm{eV}(\mathrm{C}=\mathrm{O})$ [16], $284.5 \mathrm{eV}(\mathrm{C}=\mathrm{C})$ [17], and $286 \mathrm{eV}(\mathrm{C}-\mathrm{O})$ [18]. Because the material additive contained silicide, the spectrum contains a peak at $282.9 \mathrm{eV}$ (C-Si) [19]. After heat oxidation at $800^{\circ} \mathrm{C}$, the material was mostly graphitized. The $\mathrm{C}=\mathrm{C}$ content was higher, as illustrated in Figs. 6 and 7.

In the Ols spectra, four functional groups are observed, namely $531.2 \mathrm{eV}(\mathrm{C}=\mathrm{O}), 532.2 \mathrm{eV}(\mathrm{C}-\mathrm{O})$, $531.5 \mathrm{eV}(\mathrm{P}=\mathrm{O})$, and $530.6 \mathrm{eV}(\mathrm{Si}-\mathrm{O})$ [20-24]. This indicates the change in bonding type after high temperature heat oxidation. Because the $\mathrm{Si}-\mathrm{O}-\mathrm{Si}$ structure produced by the material additive after the sol-gel reaction had both shallow and deep oxidation bonds, a series of chemical reactions occurred during high temperature heat oxidation, resulting in higher peak intensity of $=\mathrm{O}$ deep oxidation level (Fig. 8).

The P2p spectrum has peaks at $131.5 \mathrm{eV}$ (P-C) [26] and $133 \mathrm{eV}(\mathrm{P}-\mathrm{O}-\mathrm{C})$ [25] (Fig. 10). The corresponding bonds formed because of the addition of DOPO-BQ flame retardant. After high temperature deep oxidation level, the peaks were at $135 \mathrm{eV}\left(\mathrm{P}_{2} \mathrm{O}_{5}\right)$ [26] and $133.1 \pm 0.3 \mathrm{eV}\left(\mathrm{P}_{2} \mathrm{O}_{7}^{4-}\right)$ [27], corresponding to inorganic phosphides, forming char protective material. The two aforementioned inorganic phosphides were converted from the bonds before burning.

The Si2p spectra presented in Figs. 10(a) and 10(b), obtained before and after burning, respectively, have considerable differences in bonding strength. Fig. 10(a) reveals that the siloxane coupling agent caused the hydrolysis condensation reaction. Three bonds were identified: those corresponding to peaks at $100.7 \mathrm{eV}(\mathrm{Si}-\mathrm{C}), 101.6 \mathrm{eV}\left(\mathrm{Si}\left(-\mathrm{O}_{1}\right)\right)$, and $102.2 \mathrm{eV}\left(\mathrm{Si}\left(-\mathrm{O}_{2}\right)\right)$. After burning and oxidation, the $\mathrm{Si}-\mathrm{C}$ peak has disappeared whereas peaks have appeared at $101.6 \mathrm{eV}\left(\mathrm{Si}\left(-\mathrm{O}_{1}\right)\right), 102.2 \mathrm{eV}$ $\left(\mathrm{Si}\left(-\mathrm{O}_{2}\right)\right)$, and $103.5 \mathrm{eV}\left(\mathrm{Si}\left(-\mathrm{O}_{4}\right)\right)$ [28] (Fig. 10(b)). Because silicide was converted into $\mathrm{SiO}_{2}$, the peak intensity of $\mathrm{Si}\left(-\mathrm{O}_{4}\right)$ increased. This result indicates that after burning, the hybrid material PU/HBNPSi had char layers that covered and protected the substrate.

We further analyze the differences between PU/HBNPSi 10\% and PU/HBNPSi $40 \%$ at room temperature and $800^{\circ} \mathrm{C}$ for 30 mins under air atmosphere. After calculating the area ratio of each bond species individually using the Cls spectrum from Figure 6 and 7, the Cox (oxidized carbons)/Ca (aliphatic, aromatic carbons) ratio was obtained to show the anti-oxidant effect of the material [29], the results are shown in Table 3 and 4. The ratio of $\mathrm{Cox} / \mathrm{Ca}$ at room temperature of the mixed material with $10 \%$ and $40 \%$ concentration are 0.33 and 0.27 , respectively. After high temperature combustion, the ratio decreases to 0.24 and 0.11 , respectively. In summary, the higher the concentration means the better the oxidation resistance, improving the thermal stability of hybrid materials. 


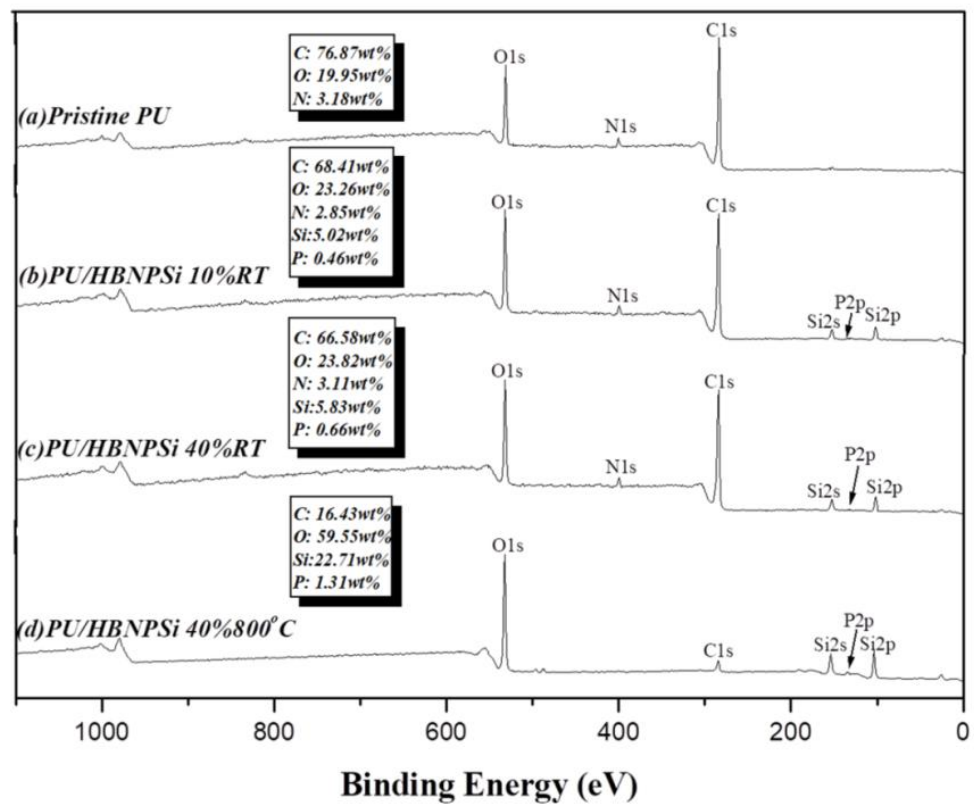

Fig. 5 XPS survey spectra of (a) pristine PU、(b) PU/HBNPSi $10 \%$ at RT、(c) PU/HBNPSi $40 \%$ at RT、(d) PU/HBNPSi $40 \%$ at $800{ }^{\circ} \mathrm{C}$.

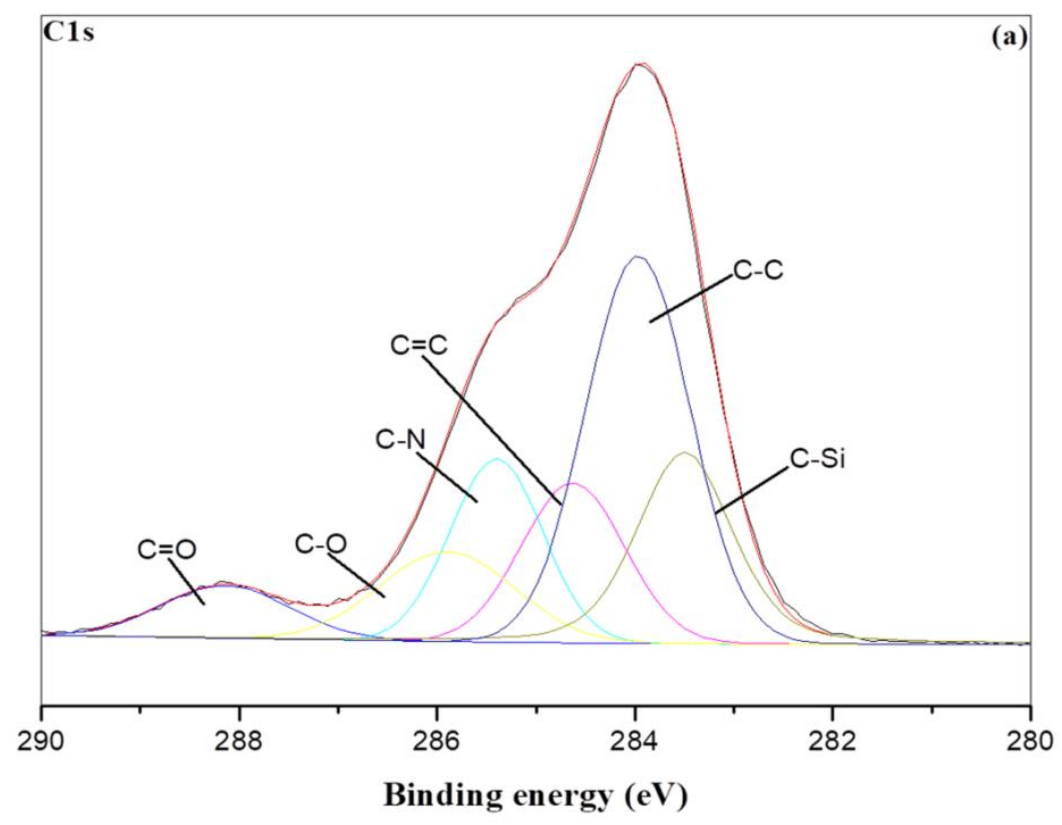




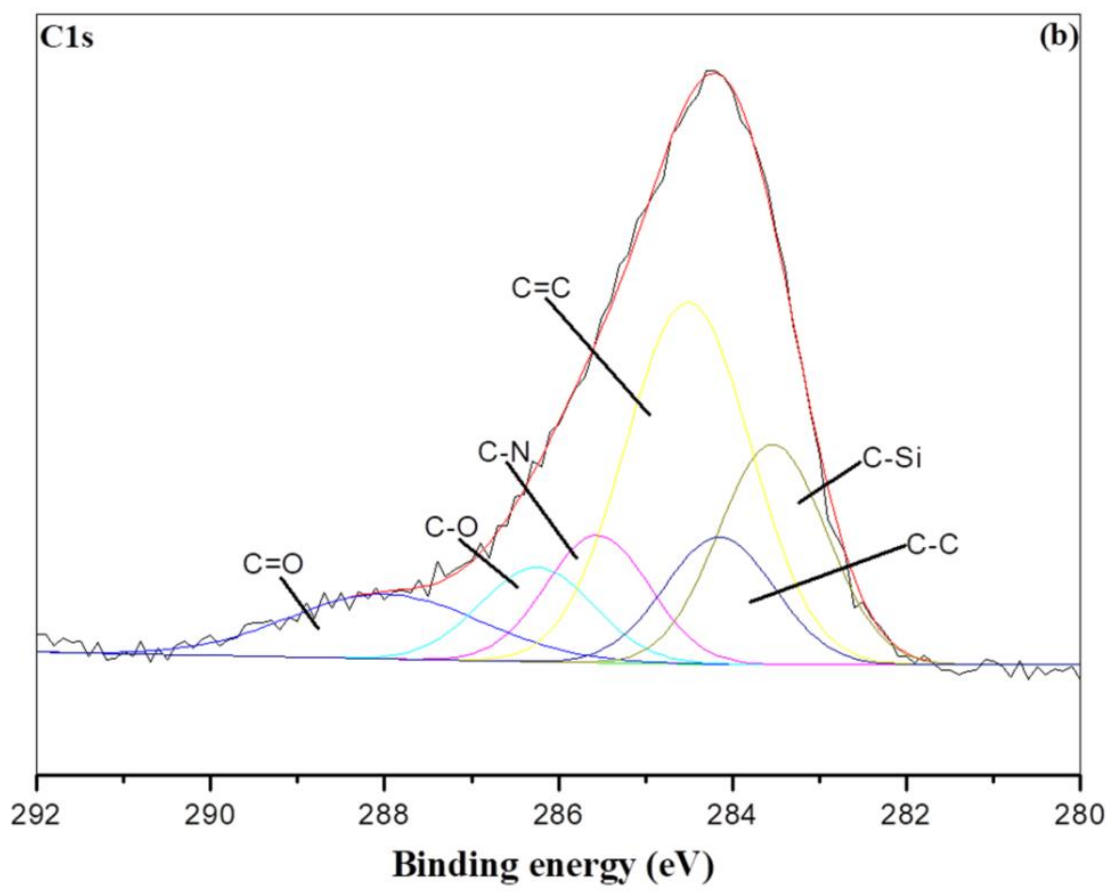

Fig. 6 C1s spectra of PU/HBNPSi 10\% (a) RT (b) under air atmosphere at $800^{\circ} \mathrm{C}$ for $30 \mathrm{~min}$.

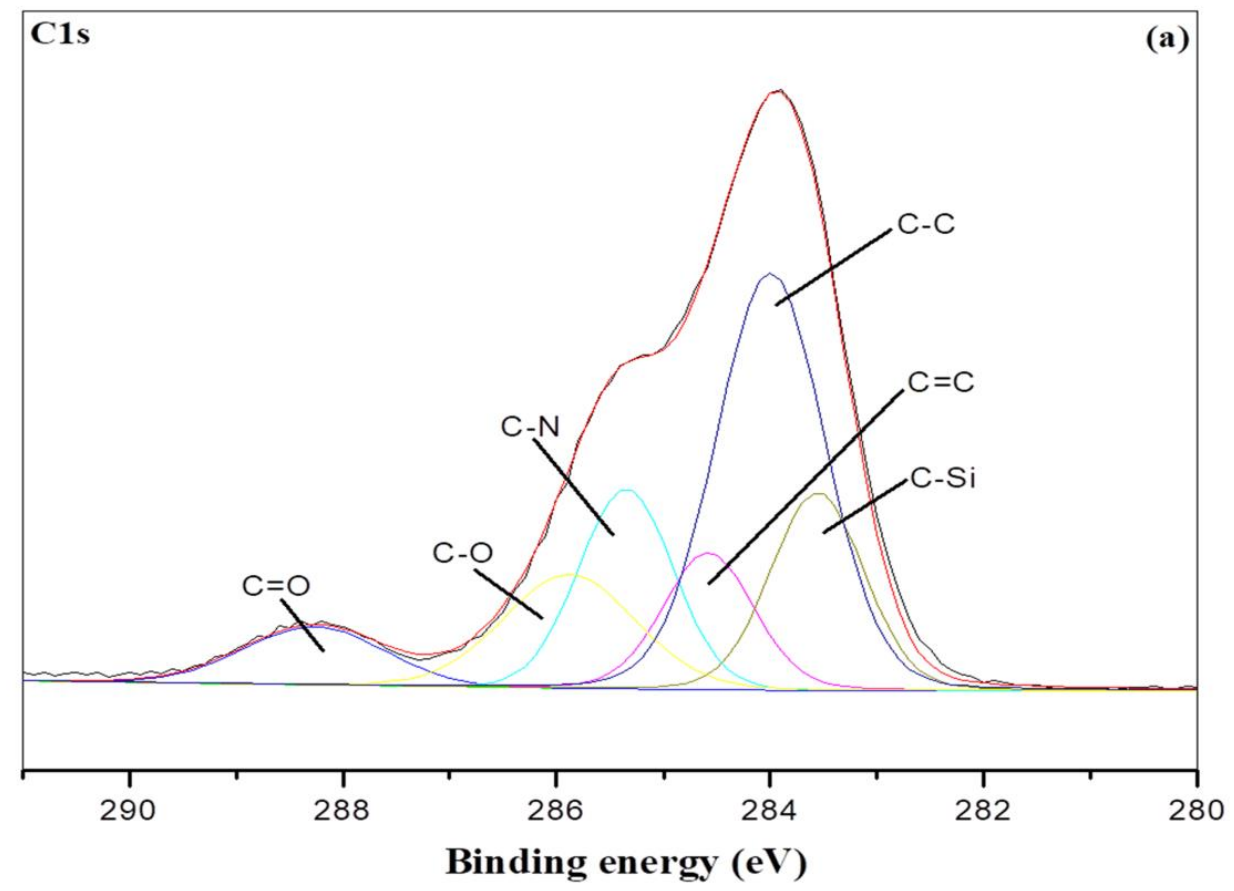




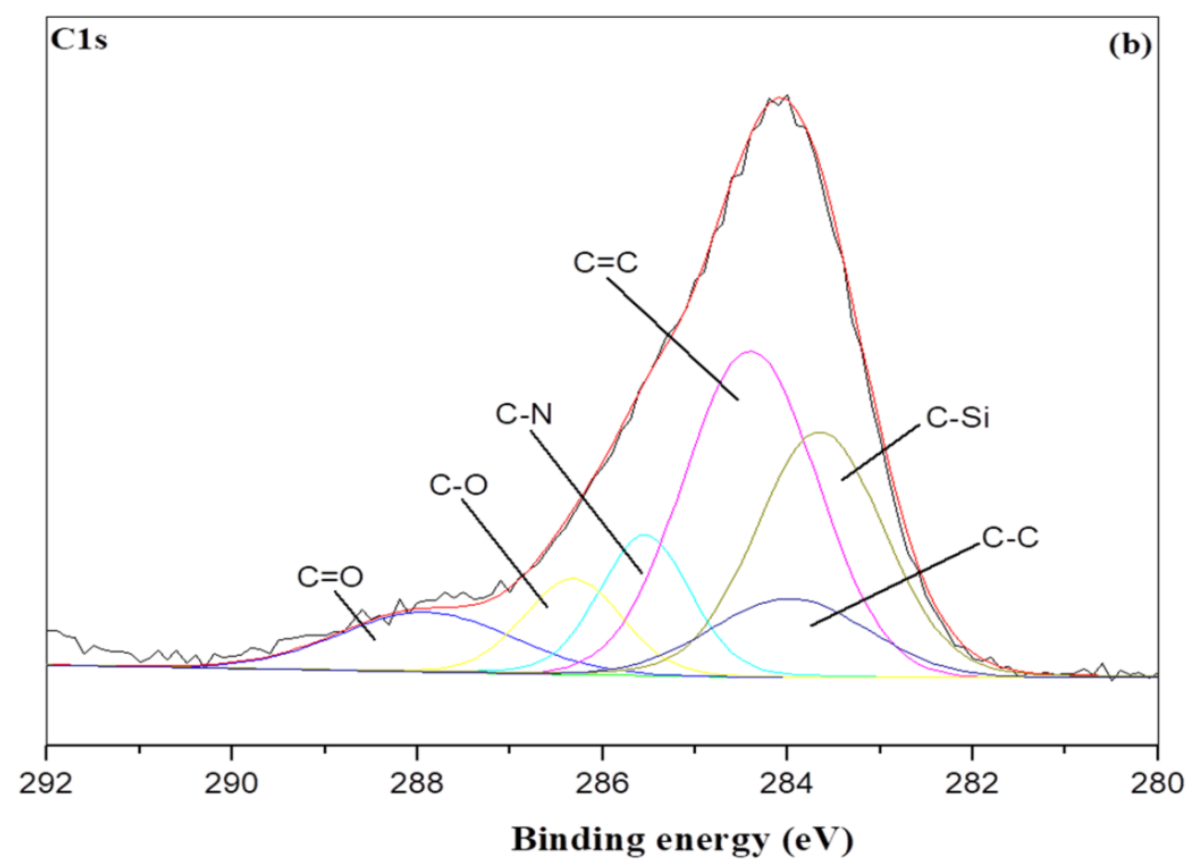

Fig. 7 C1s spectra of PU/HBNPSi 40\% (a) RT (b) under air atmosphere at $800^{\circ} \mathrm{C}$ for $30 \mathrm{~min}$.

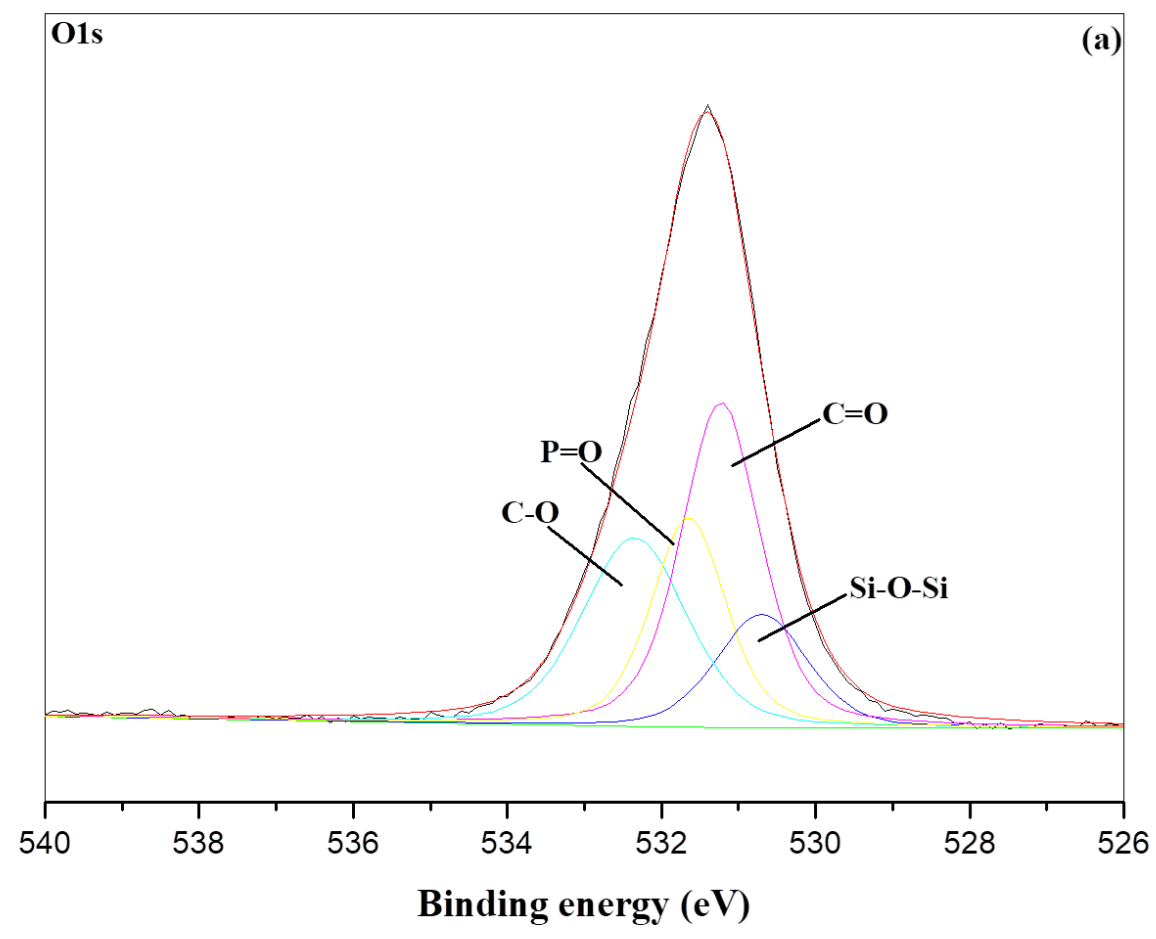




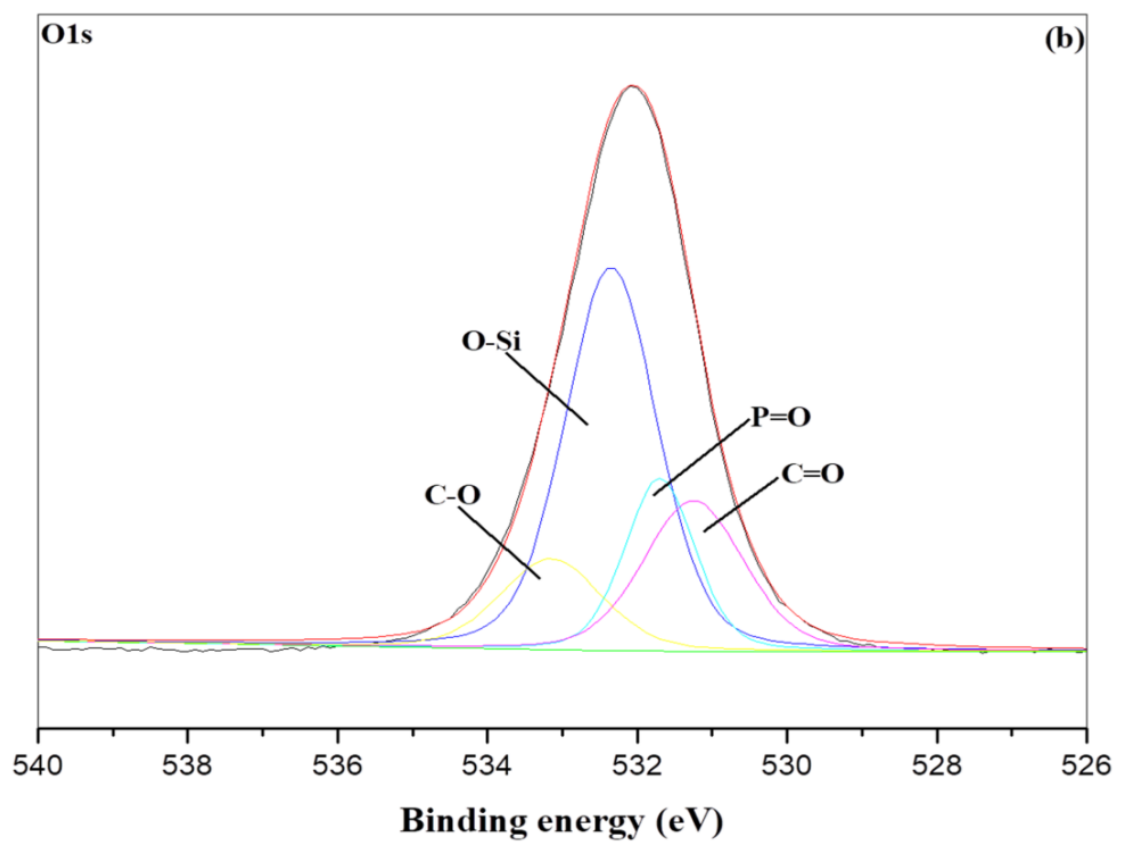

Fig. 8 O1s spectra of PU/HBNPSi 40\% (a) RT (b)under air atmosphere at $800{ }^{\circ} \mathrm{C}$ for $30 \mathrm{~min}$.

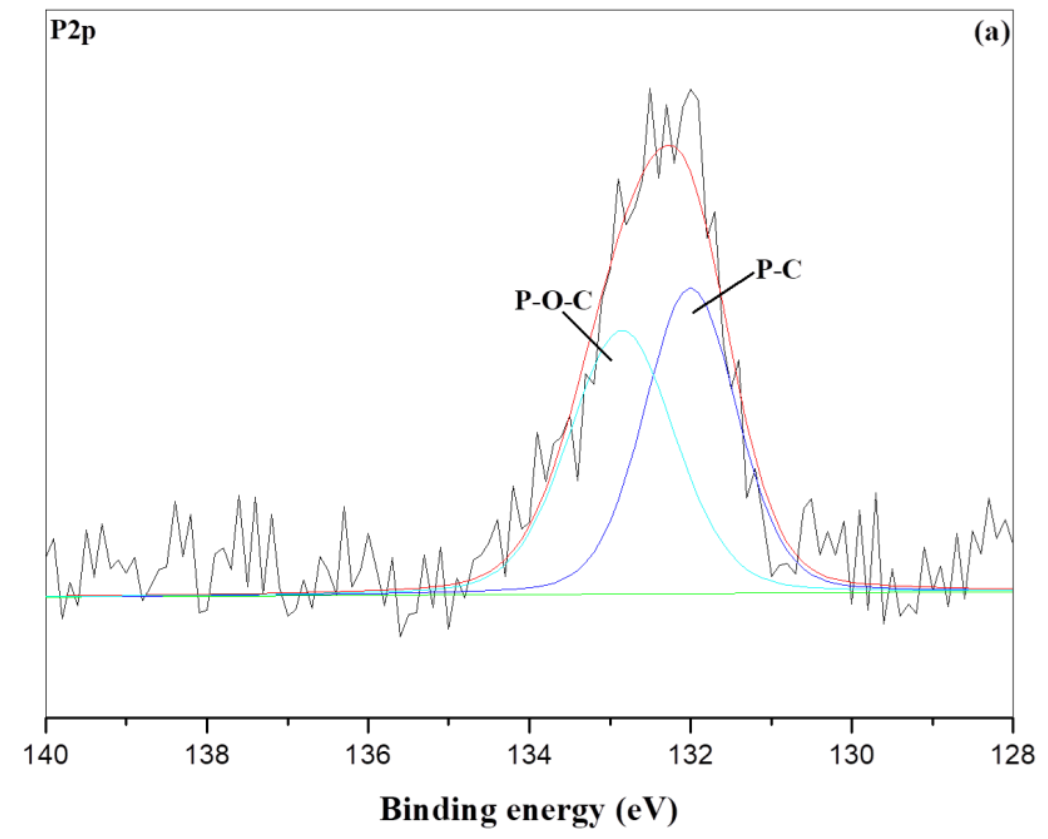




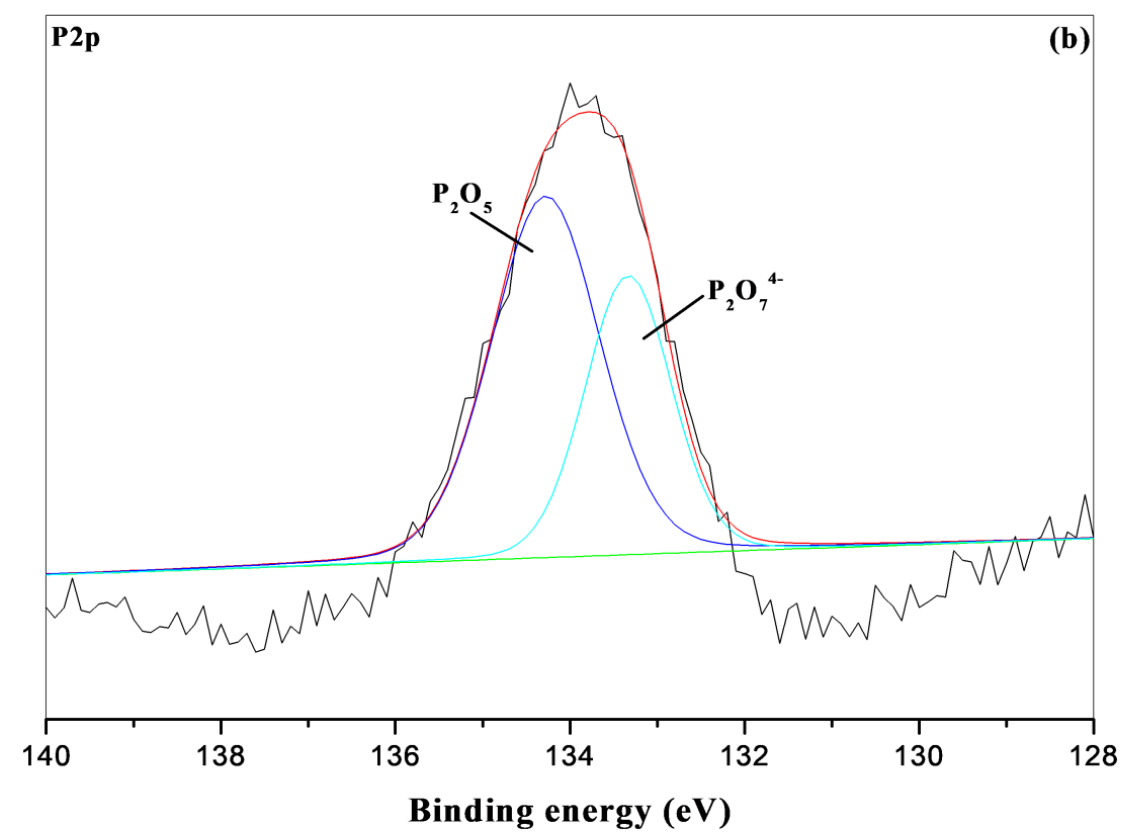

Fig. 9 P2p spectra of PU/HBNPSi $40 \%$ (a) RT (b) under air atmosphere at $800{ }^{\circ} \mathrm{C}$ for $30 \mathrm{~min}$.

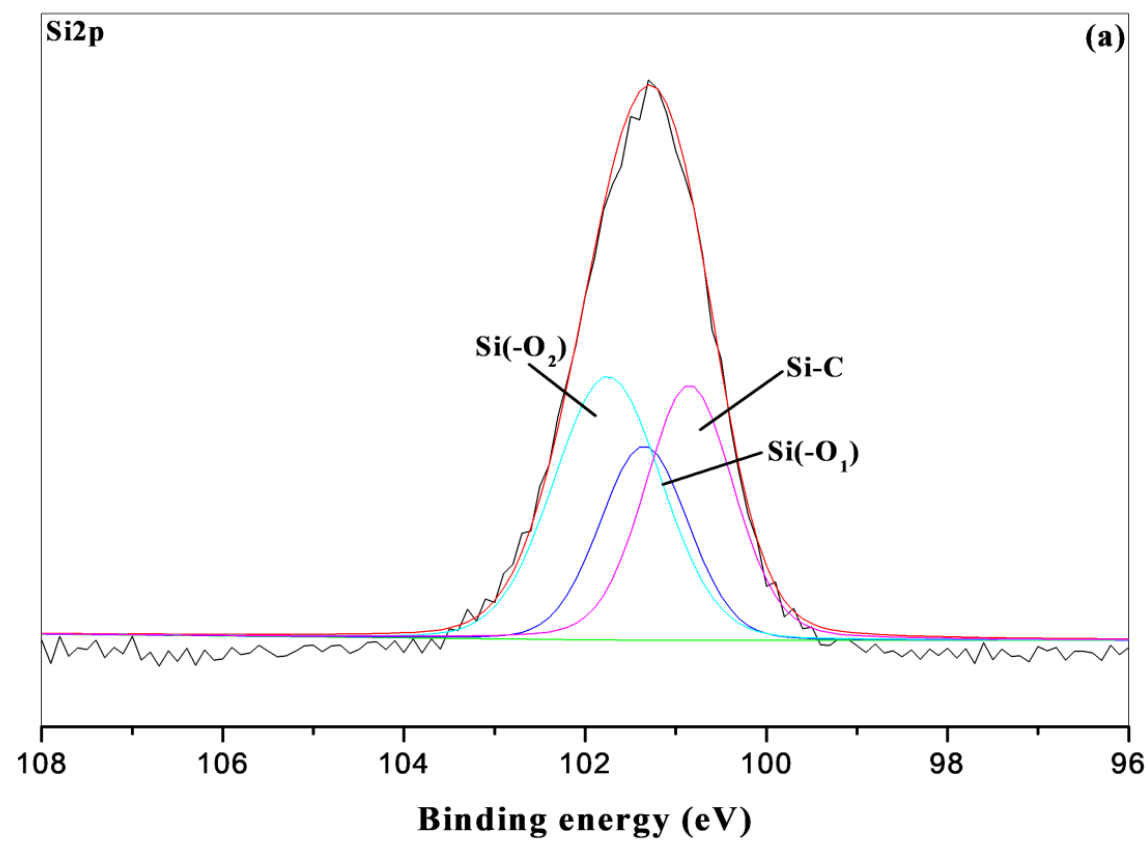




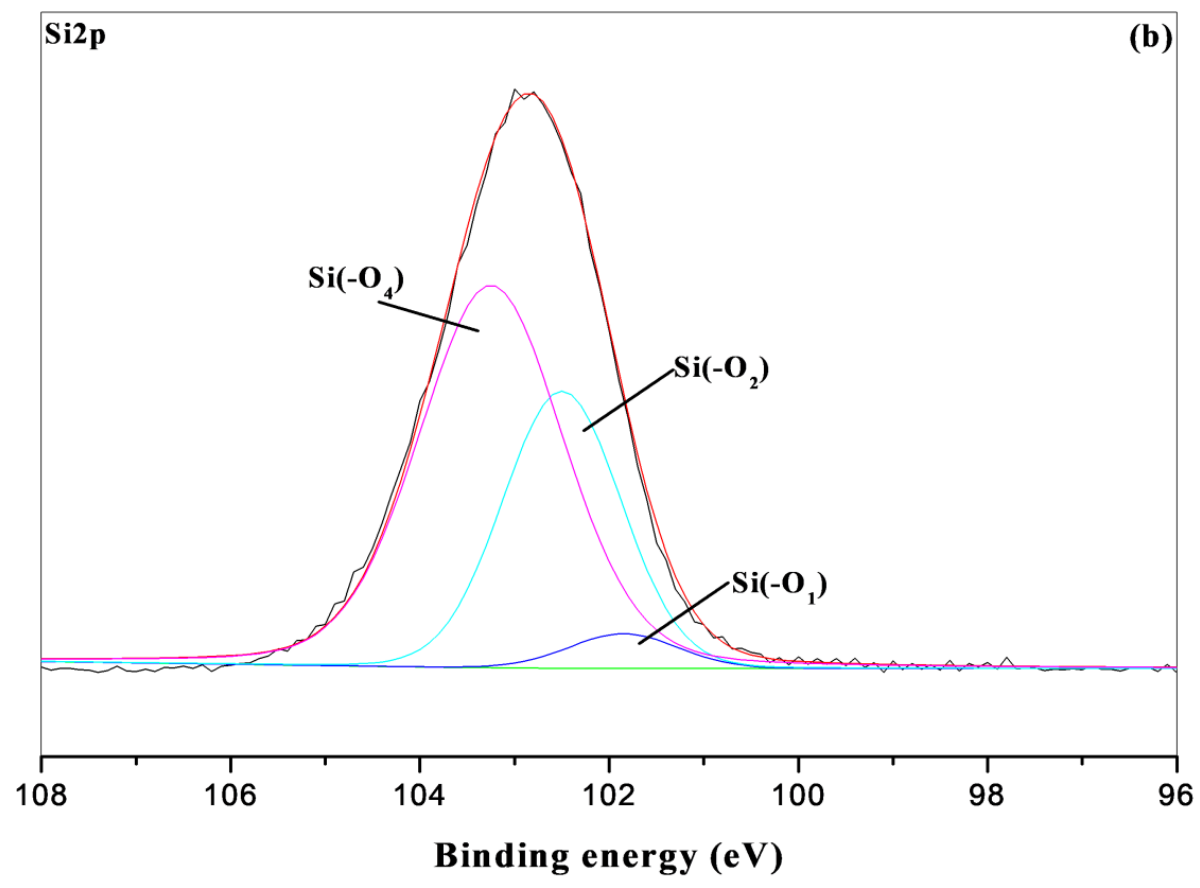

Fig. 10 Si2p spectra of PU/HBNPSi $40 \%$ (a) RT (b) under air atmosphere at $800{ }^{\circ} \mathrm{C}$ for $30 \mathrm{~min}$.

Table 3 Binding energy (eV) and relative peak intensities (\%) of the various components of C1s peak-fitted signals.

C1s

Sample NO.

$\begin{array}{llllll}\mathrm{C}-\mathrm{C} / \mathrm{C}-\mathrm{H} & \mathrm{C}-\mathrm{Si} & \mathrm{C}=\mathrm{C} & \mathrm{C}-\mathrm{N} & \mathrm{C}-\mathrm{O} & \mathrm{C}=\mathrm{O} \\ 0.31 & 0.16 & 0.11 & 0.12 & 0.15 & 0.08\end{array}$

PU/HBNPSi 10\%-RT

0.11

0.20

0.37

0.11

0.09

0.10

PU/HBNPSi 40\%-RT

0.38

0.15

0.10

0.15

0.13

0.08

PU/HBNPSi $40 \%-800^{\circ} \mathrm{C}$

0.14

0.38

0.48

0.12

0.05

0.07 
Table 4 The values of Cox/Ca of composites at RT and $800^{\circ} \mathrm{C}$.

Temperature

Sample NO.

RT

$800^{\circ} \mathrm{C}$

PU/HBNPSi 10\%

0.33

0.24

PU/HBNPSi $40 \%$

0.27

\section{Conclusions}

This study used ${ }^{29} \mathrm{Si}$ NMR to determine that the siloxane condensation degree of the PU/HBNPSi was $74.4 \%$. High condensation density indicates superior material property. P- and Si-mapping revealed that the additive HBNPSi was well dispersed and homogeneously distributed in the polymer matrix. When the HBNPSi concentration was increased, aggregation did not occur, showing that the materials and additives were compatible. The UL-94 standard was used to determine the flame retardancy of the hybrid material. Pristine PU failed to meet the standard. The $40 \%$ PU/HBNPSi, however, achieved the V-2 level, proving that the flame retardant effectively improved the flame retardancy of the pristine PU. Using XPS, char analysis was conducted on the hybrid material PU/HBNPSi to determine the correlation between char formation and the material's thermal property. Cls, Ols, and Si2p XPS spectra revealed that the phosphide and siloxane formed by burning had the effect of protecting the material. Higher concentration of HBNPSi resulted in a stronger effect, achieving high thermal stability and anti-oxidation.

Author Contributions: Conceptualization, C.-L.C.; Methodology \& Software, M.-Y.S.; Validation, C.-F.K., H.-C.K. and C.-L.C.; Formal Analysis, C.-L.C.; Investigation, C.-Y.K.; Data Curation, Writing-Original Draft Preparation, Writing-Review \& Editing, C.-L.C.

Funding: The authors would like to express their appreciation to the National Science Council of the Republic of China for financial support of this study under grant MOST-108-2221-E-241-007

Conflicts of Interest: The authors declare no conflict of interest.

\section{References}

1. Kumar, R.; Yadav, R.; Kolhe, M.A.; Bhosale, R.S.; Narayan, R. 8-Hydroxypyrene-1,3,6-trisulfonic acid trisodium salt (HPTS) based high fluorescent, $\mathrm{pH}$ stimuli waterborne polyurethane coatings. Polymer 2018, 136, 157-165.

2. Bedő, D.; Imre, B.;Domján, A.; Schöne, P.; Vancsoe, G. J.; Pukánszky, B. Coupling of poly(lactic acid) with a polyurethane elastomer by reactive processing. Eur. Polym. J 2017, 97, 409-417.

3. Zhu, S.W.; Shi, W. F. Flame retardant mechanism of hyperbranched polyurethane acrylates used for UV curable flame retardant coatings. Polym. Degrad. Stab. 2002, 75, 543-547.

4. Chen, J.; Zhang, J.; Zhu, T.; Hua, Z.; Chen, Q.; Yu, X. Blends of thermoplastic polyurethane and polyetherpolyimide: preparation and properties. Polymer 2001, 42, 1493-1500.

5. Chen, X.; Ma, C.; Jiao, C. Enhancement of flame-retardant performance of thermoplastic polyurethane with the incorporation of aluminum hypophosphite and iron-graphene. Polym. Degrad. Stab. 2016, 129, 275-285.

6. Lorenzetti, A.; Modesti, M.; Besco, S.; Hrelja, D.; Donadi, S. Influence of phosphorus valency on thermal behaviour of flame retarded polyurethane foams. Polym. Degrad. Stab. 2011, 96, 1455-1461. 
7. Zhao, Z.; Jin, Q.; Zhang, N.; Guo, X.; Yan, H. Preparation of a novel polysiloxane and its synergistic effect with ammonium polyphosphate on the flame retardancy of polypropylene. Polym. Degrad. Stab. 2018, 150, 73-85.

8. Fan, Y.; Wang, G.; Huang, X.; Bu, J.; Sun, X.; Jiang, P. Molecular structures of (3-aminopropyl)trialkoxysilane on hydroxylated barium titanate nanoparticle surfaces induced by different solvents and their effect on electrical properties of barium titanate based polymer nanocomposites. Appl. Surf. Sci. 2016, 364, 798-807.

9. Jin, Q.F.; Liao, G.X.; Jian, X.G. Synthesis and characterization of trimethoxysilyl-functionalized poly(phthalazinone ether ketone). Chin. Chem. Lett. 2007, 8, 1137-1140.

10. Paquet, O.; Brochier, Salon M.C.; Zeno, E.; Belgacem, M.N. Hydrolysis-condensation kinetics of 3-(2-amino-ethylamino)propyl-trimethoxysilane. Mater. Sci. Eng. C 2012, 32, 487-493.

11. Velencoso, M.M.; Ramos, J.M.; Klein, R.; Lucas, A.D.; Rodriguez, F.J. Thermal degradation and fire behaviour of novel polyurethanes based on phosphate polyols. Polym. Degrad. Stab. 2014, 101, 40-51.

12. Shi, Y.; Wang, G. The novel silicon-containing epoxy/PEPA phosphate flame retardantfor transparent intumescent fire resistant coating. Appl. Surf. Sci. 2016, 385, 453-463.

13. Wu, C.S.; Liu, Y.L.; Chiu Y.S. Epoxy resins possessing flame retardant elements from silicon incorporated epoxy compounds cured with phosphorus or nitrogen containing curing agents. Polymer 2002, 43, 4277-4284.

14. Liu, W.; Chen, D.Q.; Wang, Y.Z.; Wang, D.Y.; Qu, M.H. Char-forming mechanism of a novel polymeric flame retardant with char agent. Polym. Degrad. Stab. 2007, 92, 1046-1052.

15. Chen, X.; Hu, Y.; Jiao, C.; Song, L. Preparation and thermal properties of a novel flame-retardant coating. Polym. Degrad. Stab. 2007, 92, 1141-1150.

16. Wang, Z.; Wei, P.; Qian, Y.; Liu, J. The synthesis of a novel graphene-based inorganic-organic hybrid flame retardant and its application in epoxy resin. Composites B 2014, 60, 341-349.

17. Teng, C.C.; Ma, C.C.M.; Lu, C.H.; Yang, S.Y.; Lee, S.H.; Hsiao, M.C.; Yen, M.Y.; Chiou, K.C.; Lee, T.M. Thermal conductivity and structure of non-covalent functionalized graphene/epoxy composites. Carbon 2011, 49, 5107-5116.

18. Zhou, S.; Song, L.; Wang, Z.; Hu, Y.; Xing, W. Flame retardation and char formation mechanism of intumescent flame retarded polypropylene composites containing melamine phosphate and pentaerythritol phosphate. Polym. Degrad. Stab. 2008, 93, 1799-1806.

19. Dutkiewicz, M.; Przybylak, M.; Januszewski, R.; Maciejewski, H. Synthesis and flame retardant efficacy of hexakis(3-(triethoxysilyl)propyloxy)cyclotriphosphazene/silica coatings for cotton fabrics. Polym. Degrad. Stab. 2018, 148, 10-18.

20. Kim, H.S.; Kim H.J. Enhanced hydrolysis resistance of biodegradable polymers and bio-composites. Polym. Degrad. Stab. 2008, 93, 1544-1553.

21. Kannan, G.A.; Choudhury, N.R.; Dutta, K.N. Synthesis and characterization of methacrylate phospho-silicate hybrid for thin film applications. Polymer 2007, 48, 7078-7086.

22. Chana, M.l.; Lau, K.T.; Wong T.T.; Cardona, F. Interfacial bonding characteristic of nanoclay/polymer composites. Appl. Surf. Sci. 2011, 258, 860-864.

23. Chai, B.; Yan, J.; Wang, C.; Ren, Z.; Zhu, Y. Enhanced visible light photocatalytic degradation of Rhodamine B over phosphorus doped graphitic carbon nitride. Appl. Surf. Sci. 2017, 391, 376-383.

24. Zhang, W.; Li, X.; Fan, H.; Yang, R. Study on mechanism of phosphorus-silicon synergistic flame retardancy on epoxy resins. Polym. Degrad. Stab. 2012, 97, 2241-2248.

25. Zhang, Y.; Ni, Y. P.; He, M.X.; Wang, X. L.; Chen, L.; Wang, Y. Z. Phosphorus-containing copolyesters: The effect of ionic group and its analogous phosphorus heterocycles on their flame-retardant and anti-dripping performances. Polymer 2015, 60, 50-61.

26. Huang, C.; Puziy, M.A.; Sun, T.; Poddubnaya, I.O.; Fabián, S.G.; Juan, M.D.T.; Denisa, H.J. Capacitive Behaviours of Phosphorus-Rich Carbons Derived from Lignocelluloses. Electrochim. Acta, 2014, 137, 219-227.

27. Brookes, N.P.; Fraser, S.; Short, D.R.; Hanley, L.; Fuoco, E.; Roberts, A.; Hutton, S. The effect of ion energy on the chemistry of air-aged polymer films grown from the hyperthermal polyatomic ion Si2OMe5+. J. Electron. Spectrosc. Relat. Phenom. 2001, 121, 281-297. 
28. Brookes, N. P.; Fraser, S.; Short, D. R.; Hanley, L.; Fuoco, E.; Roberts, A.; Hutton, S. The effect of ion energy on the chemistry of air-aged polymer films grown from the hyperthermal polyatomic ion $\mathrm{Si}_{2} \mathrm{OMe}^{5+}$. J. Electron. Spectrosc. Relat. Phenom. 2001, 121, 281-297.

29. Wang, X.; Wu, L.; Li, J. Synergistic flame retarded poly(methyl methacrylate) by nano-ZrO2 and triphenylphosphate. J. Therm. Anal. Calorim. 2011, 103, 741-746. 